\title{
Electrochemical Activation of Self-Assembled Monolayers for Binding of Effectors
}

\section{- Supporting information -}

Aleksandra Markovic, Leon Buschbeck, Izabella Brand, Carsten Dosche, Jens Christoffers, Gunther Wittstock*

Carl von Ossietzky University of Oldenburg, School of Mathematics and Science, Chemistry Department, D-26111 Oldenburg, Germany

*Corresponding author

E-mail: wittstock@uol.de

\section{Content}

SI-1 Organic Synthesis

SI-2 Activation of the SAM of Compound 2 in $0.1 \mathrm{M} \mathrm{H}_{2} \mathrm{SO}_{4}$

SI-3 Calculation of Interfacial Concentration

SI-4 Estimation of the Cross Sectional Area of the Terminal Group in Compound 2

SI-5 Assignment of the IR Absorption Modes of Compound 2 in the SAM

SI-6 PM IRRA Spectra of the SAM after Exposure to $0.1 \mathrm{M} \mathrm{HClO}_{4}$ at Open Circuit Potential

SI-7 Atomic Ratio S:F after Conjugate Addition of 3-(Trifluoromethyl)aniline to the Activated SAM

SI-8 Additional Example for Conjugate Addition 


\section{SI-1 Organic Synthesis}

General synthetic methods: Preparative column chromatography was carried out using Merck $\mathrm{SiO}_{2}(35-70 \mu \mathrm{m}$, type $60 \mathrm{~A})$ with hexanes (mixture of isomers, bp. 64-71 ${ }^{\circ} \mathrm{C}$ ) and EtOAc as eluents. TLC was performed on aluminum plates coated with $\mathrm{SiO}_{2} \mathrm{~F}_{254} \cdot{ }^{1} \mathrm{H}$ and ${ }^{13} \mathrm{C} \mathrm{NMR}$ spectra were recorded on a Bruker Avance DRX 500 instrument. Multiplicities of carbon signals were determined with DEPT experiments. HRMS spectra of products were obtained with a Thermo Scientific DFS (EI) spectrometer. IR spectra were recorded on a Bruker Tensor 27 spectrometer equipped with a diamond ATR unit. UV/Vis spectra were recorded with a Shimadzu UV-1800, fluorescence spectra with a Shimadzu RF-5301PC spectrometer. The preparation of starting material 1 was reported before. ${ }^{1}$ COMU [(1-cyano-2-ethoxy-2oxoethylideneaminooxy)(dimethylamino)(morpholino)carbenium hexafluorophosphate], DIPEA (ethyldiisopropylamine) and ALA (racemic $\alpha$-lipoic acid) were commercially available.

Synthesis of rac-Diethyl 2-\{3-[5-(1,2-dithiolan-3-yl)pentanoylamino]propylamino\}-5[(tert-butoxycarbonyl)amino]terephthalate (2).<smiles>CCCNc1cc(C(=O)OCC)c(NCCCN)cc1C(=O)OCC</smiles>

1

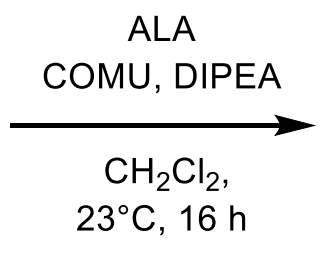

$23^{\circ} \mathrm{C}, 16 \mathrm{~h}$<smiles>CCOC(=O)c1cc(N[13C](=O)[O-])c(C(=O)OCC)cc1NCCCNC(=O)CCCCC1CCSS1</smiles>

COMU (0.72 mmol, $308 \mathrm{mg}, 3.0 \mathrm{eq})$ was added to a solution of ALA (0.48 mmol, $99 \mathrm{mg}, 2.0$ eq) and DIPEA $(0.72 \mathrm{mmol}, 93 \mathrm{mg}, 3.0 \mathrm{eq})$ in $\mathrm{CH}_{2} \mathrm{Cl}_{2}(4 \mathrm{~mL})$ and the mixture was stirred for $1 \mathrm{~h}$ at ambient temperature. The solution was added dropwise to a suspension of amine $\mathbf{1}(0.24$ mmol, $100 \mathrm{mg}, 1.0 \mathrm{eq})$ in $\mathrm{CH}_{2} \mathrm{Cl}_{2}(4 \mathrm{~mL})$ an it was stirred for $16 \mathrm{~h}$ at ambient temperature. It was diluted with $\mathrm{CH}_{2} \mathrm{Cl}_{2}(7 \mathrm{~mL})$ and the organic layer was washed with water $(4 \times 25 \mathrm{~mL})$ dried over $\mathrm{MgSO}_{4}$, filtered and all volatile materials were removed under reduced pressure. The residue was chromatographed $\left(\mathrm{SiO}_{2}\right.$, hexanes/EtOAc 1:2, $\left.\mathrm{R}_{\mathrm{f}}=0.35\right)$ to yield compound 2 (35 mg, $60 \mu \mathrm{mol}, 25 \%)$ as a red resin. ${ }^{1} \mathrm{H} \mathrm{NMR}\left(500 \mathrm{MHz}, \mathrm{CDCl}_{3}\right): \delta=1.33-1.46(\mathrm{~m}, 2 \mathrm{H})$, $1.39(\mathrm{t}, J=7.2 \mathrm{~Hz}, 3 \mathrm{H}), 1.41(\mathrm{t}, J=7.2 \mathrm{~Hz}, 3 \mathrm{H}), 1.51(\mathrm{~s}, 9 \mathrm{H}), 1.59-1.71(\mathrm{~m}, 4 \mathrm{H}), 1.84-1.93$ (m, 3H), 2.13-2.22 (m, 2H), 2.40-2.48 (m, 1H), 3.06-3.11 (m, 1H), 3.12-3.19 (m, 1H), 3.24 
(t, $J=6.5 \mathrm{~Hz}, 2 \mathrm{H}), 3.40(\mathrm{q}, J=6.5 \mathrm{~Hz}, 2 \mathrm{H}), 3.51-3.58(\mathrm{~m}, 1 \mathrm{H}), 4.34(\mathrm{q}, J=7.1 \mathrm{~Hz}, 2 \mathrm{H}), 4.38$ (q, $J=7.1 \mathrm{~Hz}, 2 \mathrm{H}), 5.83$ (t, $J=5.5 \mathrm{~Hz}, 1 \mathrm{H}), 7.25$ (s, 1H), 7.33 (br.s, 1H), 8.80 (s, 1H), 9.45 (s, 1H) ppm. ${ }^{13} \mathrm{C}\left\{{ }^{1} \mathrm{H}\right\} \mathrm{NMR}\left(125 \mathrm{MHz}, \mathrm{CDCl}_{3}\right): \delta=14.35\left(\mathrm{CH}_{3}\right), 14.46\left(\mathrm{CH}_{3}\right), 25.50\left(\mathrm{CH}_{2}\right) 28.51$ $\left(3 \mathrm{CH}_{3}\right), 29.01\left(\mathrm{CH}_{2}\right), 29.16\left(\mathrm{CH}_{2}\right), 34.71\left(\mathrm{CH}_{2}\right), 36.57\left(\mathrm{CH}_{2}\right), 37.83\left(\mathrm{CH}_{2}\right), 38.57\left(\mathrm{CH}_{2}\right), 40.34$ $\left(\mathrm{CH}_{2}\right), 41.10\left(\mathrm{CH}_{2}\right), 56.51(\mathrm{CH}), 61.17\left(\mathrm{CH}_{2}\right), 61.79\left(\mathrm{CH}_{2}\right), 80.18(\mathrm{C}), 112.94(\mathrm{CH}), 115.24$ (C), 121.49 (C), 122.88 (CH), 129.59 (C), 145.27 (C), 153.26 (C), 167.43 (C), 168.15 (C), 173.19 (C) ppm. IR (ATR): $\lambda^{-1}=3340$ (br), $1277(w), 2930(w), 2861(w), 1722(w), 1681$ (m), 1537 (s), 1461 (w), 1421 (m), 1391 (w), 1367 (m), 1325 (w), 1214 (vs), 1156 (vs), 1123 (m), 1102 (s), 1070 (m), 1044 (w), 1020 (m), 913 (w), 846 (m), 790 (m), 747 (w), 640 (w), 596

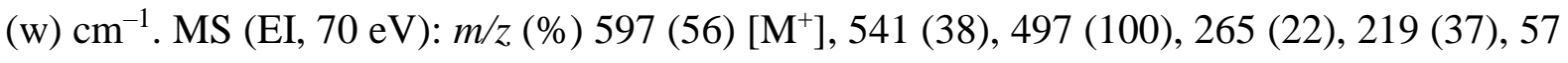
(38), 40 (60). HRMS (EI): calcd. 597.2537 (for $\mathrm{C}_{28} \mathrm{H}_{43} \mathrm{~N}_{3} \mathrm{O}_{7} \mathrm{~S}_{2}{ }^{+}$), found $597.2538\left[\mathrm{M}^{+}\right]$. UV/Vis $\left(\mathrm{CH}_{2} \mathrm{Cl}_{2}\right): \lambda_{\max }(\lg \varepsilon)=430 \mathrm{~nm}(3.80)$; fluorescence $\left(\mathrm{CH}_{2} \mathrm{Cl}_{2}\right): \lambda_{\mathrm{em}}=508 \mathrm{~nm}, \lambda_{\mathrm{ex}}=430 \mathrm{~nm}, \Phi$ $=0.30 . \mathrm{C}_{28} \mathrm{H}_{43} \mathrm{~N}_{3} \mathrm{O}_{7} \mathrm{~S}_{2}\left(597.79 \mathrm{~g} \mathrm{~mol}^{-1}\right)$ 


\section{SI-2 Activation of the SAM of Compound 2 in $0.1 \mathrm{M} \mathrm{H}_{2} \mathrm{SO}_{4}$}

Cyclic voltammogram in Figure S1 shows the behaviour of the backfilled surfaces of compound 2 in $0.1 \mathrm{M} \mathrm{H}_{2} \mathrm{SO}_{4}$. Detailed explanation can be found in main manuscript.

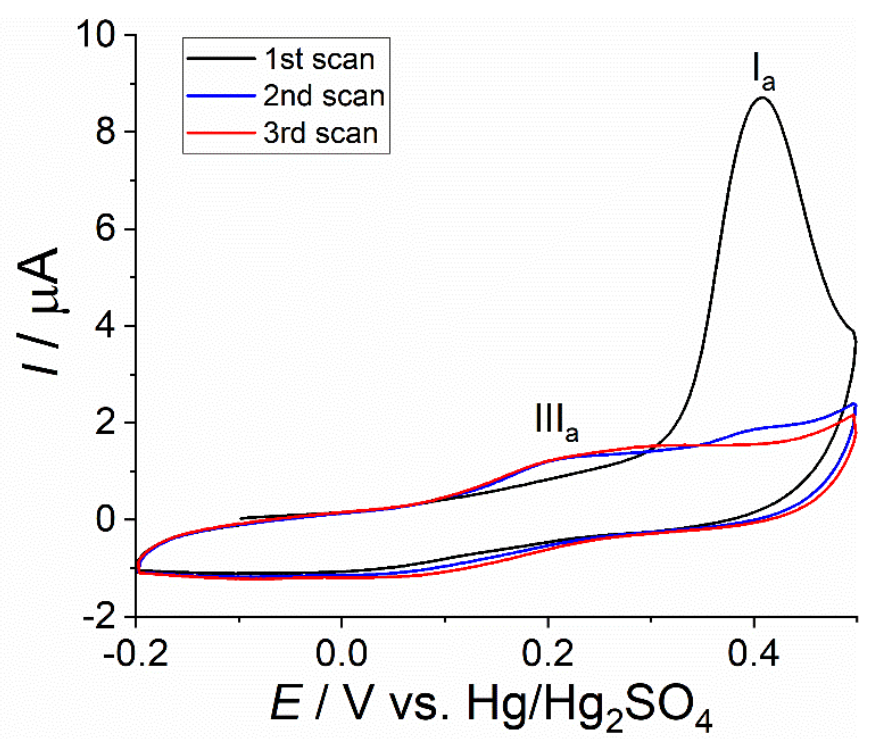

Figure S1. Inintial three CVs of the SAM of compound 2 backfilled with 1-decanethiol on an $\mathrm{Au}$ electrode in $0.1 \mathrm{M} \mathrm{H}_{2} \mathrm{SO}_{4}, v=0.05 \mathrm{Vs}^{-1}$. 


\section{SI-3 Calculation of Interfacial Concentration}

The charge of the activation peak $\left(\mathrm{I}_{\mathrm{a}}\right)$ in the first and second potential cycles of Figure 1 were added to calculate the charge $(Q)$ of the redox reaction. The number of electrons transferred in the electrochemical reaction was assumed to be $n=2$ based on the consideration of the fwhm of $75 \mathrm{mV}$. The interfacial concentration of electrochemically addressable compound 2 in the mixed SAM was calculated using equation S1.

$$
\Gamma_{2}=\frac{\frac{1}{v_{0.23 \mathrm{~V}}} \int_{n A_{\text {geom }}}^{0.50 \mathrm{~V}} I(E) d E}{n .05 \mathrm{~V} \mathrm{~s}^{-1} \cdot 2 \cdot 96485 \mathrm{As} \mathrm{mol}^{-1} \cdot 0.2826 \mathrm{~cm}^{2}}=2.48 \times 10^{-10} \mathrm{~mol} \mathrm{~cm}^{-2}
$$

After electrochemical activation, the surface concentration of the new redox couple was estimated in the same way assuming $n=2$ from the consideration of the fwhm in Figure $2 \mathrm{a}$ of the main text.

$$
\Gamma_{\text {act }}=\frac{\frac{1}{v_{-0.077 \mathrm{~V}}} \int_{n F A_{\text {geom }}}^{0.137 \mathrm{~V}} I(E) d E}{0.05 \mathrm{~V} \mathrm{~s}^{-1} \cdot 2 \cdot 96485 \mathrm{As} \mathrm{mol}^{-1} \cdot 0.2826 \mathrm{~cm}^{2}}=2.60 \times 10^{-11} \mathrm{molcm}^{-2}
$$




\section{SI-4 Estimation of the Cross Sectional Area of the Terminal Group in Compound}

\section{2}

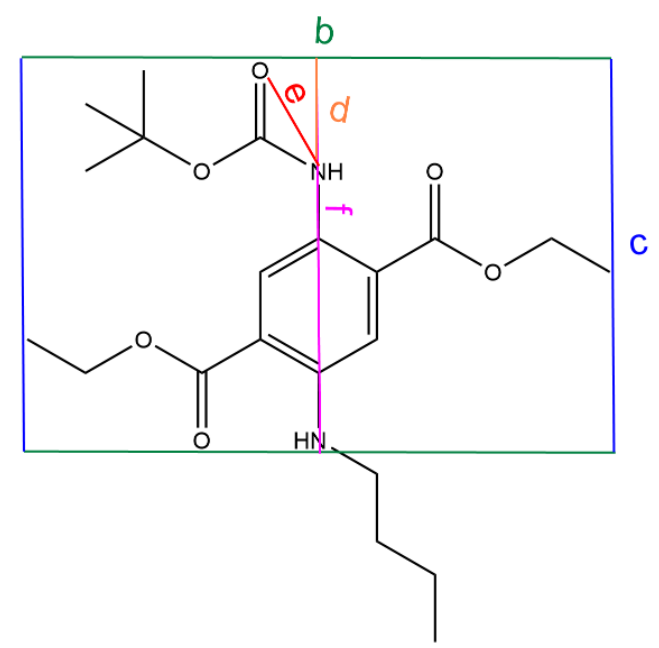

Scheme S1. Schematic representation of cross sectional area of the DAT moiety of compound 2 oriented parallel to the substrate surface.

The blue and green rectangle represents the cross sectional area of the head group. For the calculation of the cross sectional area of the head group, the sides of the rectangle ( $b$ and $c$ in Scheme S1) were taken from the crystal structure of diethyl 2,5-bis(phenylamino)benzene-1,4dicarboxylate. The crystallographic data for this compound are deposited under CCDC2012244 at The Cambridge Crystallographic Data Centre and can be obtained free of charge via www.ccdc.cam.ac.uk. Compound 2 has not the same, but a similar structure as diethyl 2,5bis(phenylamino)benzene-1,4-dicarboxylate. Both molecules have an identical length $b$. The side $c$ in Scheme S1 was calculated using bond lengths and bond angles. Firstly, the dimension of $f$ and $e$ in in Scheme $\mathrm{S} 1$ were calculated using simple geometric rules and bond lengths from http://hydra.vcp.monash.edu.au/modules/mod2/bondlen.html). The bond angles were taken from Chem 3D version 17.1. The dimension of one part of the side of rectangle was approximated and marked orange $(d)$. The value was approximated based on the calculated length of the red line $(e)$ in Scheme S1. Side $c$ of the rectangle was calculated as

$$
c=e+f=7.97 \AA \text {, }
$$

where $f=5.64 \AA$ and $e=2.33 \AA$.

The area is calculated as:

$$
A_{\text {paral }}=b \cdot c=10.05 \AA \cdot 7.97 \AA=80.10 \AA^{2}=0.80 \mathrm{~nm}^{2} .
$$


where $b=10.05 \AA$ and $c=7.97 \AA$.

For a perpendicular orentation of the head group the required area $A_{\text {perp }}$ is obtained from the geometry in Scheme S2.

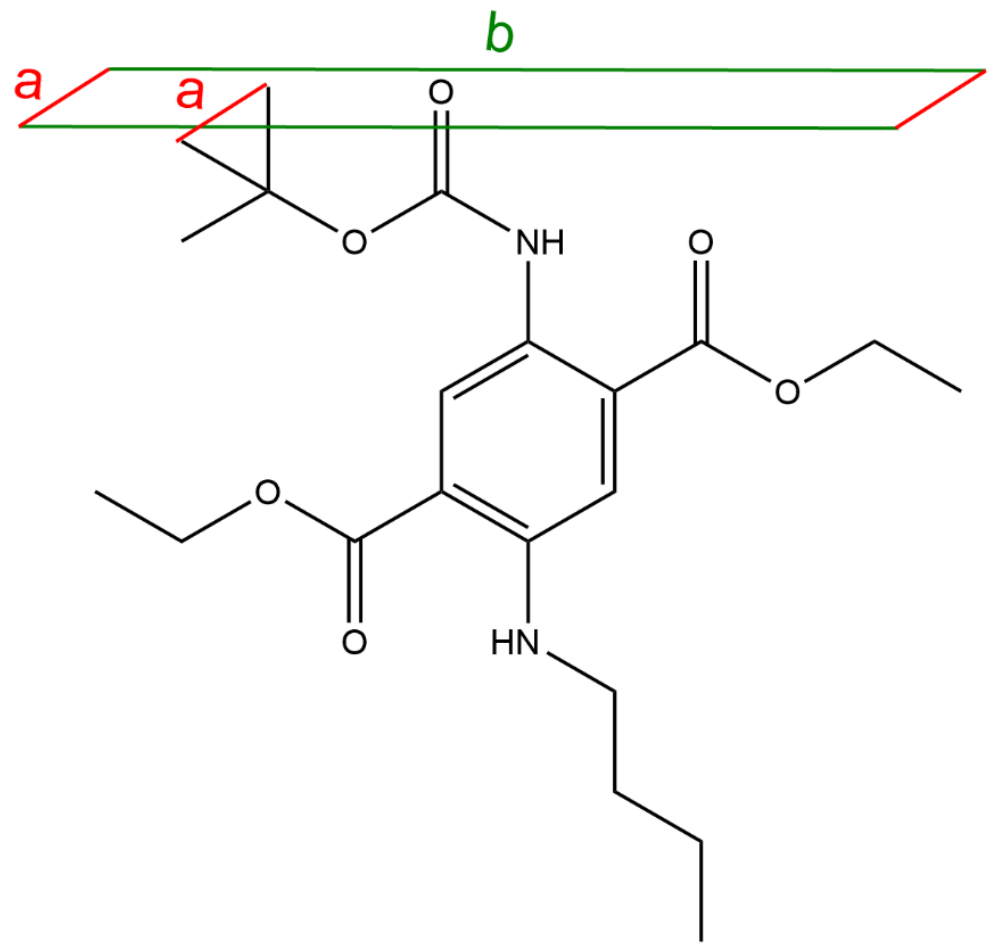

Scheme S2. Schematic representation of cross sectional area of the DAT moiety of compound 2 with perpendicular orientation to the surface.

The cross sectional area $A_{\text {perp }}$ is approximated as a rectangle with the lengths $b$ and $a$ (as in Scheme S2). The side $b$ in indentical to one in S1. The side $a$ was calculated as the C-C distance between the terminal carbon atoms of the Boc group and $\mathrm{H}-\mathrm{C}$ bond length was added to every carbon atom.

$$
a=2.52 \AA+1.09 \AA+1.09 \AA=4.70 \AA
$$

where $2.52 \AA$ is $\mathrm{C}$-C distance and $1.09 \AA \mathrm{H}-\mathrm{C}$ distance.

The area is calculated as:

$$
A_{\text {perp }}=b \cdot a=10.05 \AA \cdot 4.70 \AA=47.24 \AA^{2}=0.47 \mathrm{~nm}^{2} \text {. }
$$

where $b=10.05 \AA$ and $a=4.70 \AA$. 


\section{SI-5 Assignment of the IR Absorption Modes of Compound 2 in the SAM}

The assingment of the IR absorption modes of compound $\mathbf{2}$ in a freshly prepared monolayer on the gold surface is given in Table S1.

Table S1. Assignment of the IR absorption bands of the initial SAM of compound 2 from Figure 4 of the main text.

\begin{tabular}{|c|c|c|c|}
\hline Number & $\tilde{v} / \mathbf{c m}^{-1}$ & Band assignment & Ref. \\
\hline 1 & $3010-3009$ & $v(\mathrm{CH})$ aromatic ring & 2,3 \\
\hline 2 & 2985-2983 & $\mathrm{v}_{\mathrm{as}}\left(\mathrm{O}-\mathrm{CH}_{3}\right)$ & 4 \\
\hline 3 & 2972 & $v_{\text {as }}\left(\mathrm{C}-\mathrm{CH}_{3}\right)$ & \\
\hline 4 & $2929-2925$ & $\mathrm{v}_{\mathrm{as}}\left(\mathrm{CH}_{2}\right)$ & \\
\hline 5 & $2878-2876$ & $v_{\mathrm{s}}\left(\mathrm{CH}_{3}\right)$ & 2,3 \\
\hline 6 & $2855-2854$ & $v_{\mathrm{s}}\left(\mathrm{CH}_{2}\right)$ & 2,3 \\
\hline 7 & $1730-1729$ & $v(\mathrm{C}=\mathrm{O})$ ester & 2,3 \\
\hline 8 & $1688-1689$ & $v(\mathrm{C}=\mathrm{O})$ amide and carbamate & 2,3 \\
\hline 9 & $1546-1544$ & in plane $v(\mathrm{CC})$ atomatic ring & 2,3 \\
\hline 10 & $1423-1421$ & in plane $v(\mathrm{CC})$ aromatic ring & 2,3 \\
\hline 11 & 1393 & in plane $v(\mathrm{CC})$ aromatic ring & 2,3 \\
\hline 12 & $1368-1366$ & $\delta_{\text {as }}\left(\mathrm{CH}_{3}\right), v(\mathrm{C}-\mathrm{O})$ carbamide & 2,3 \\
\hline 13 & $1268-1266$ & $v(\mathrm{C}-\mathrm{O})$ carbamide, $v(\mathrm{C}-\mathrm{N}), t\left(\mathrm{CH}_{2}\right)$ & 2,3 \\
\hline 14 & $1244-1243$ & $v(\mathrm{C}-\mathrm{O})$ ester, $v(\mathrm{C}-\mathrm{N}), v(\mathrm{C}-\mathrm{C})$ & 2,3 \\
\hline 15 & $1225-1224$ & $\begin{array}{l}v(\mathrm{C}-\mathrm{O}) \text { ester }+ \text { out of plane } v(\mathrm{CC}) \text { aromatic } \\
\text { ring }\end{array}$ & 2,3 \\
\hline 16 & $1176-1175$ & out of plane $v(C C)$ aromatic ring & 2,3 \\
\hline 17 & $1161-1158$ & out of plane $v(C C)$ aromatic ring & 2,3 \\
\hline
\end{tabular}




\section{SI-6 PM IRRA Spectra of the SAM after Exposure to $0.1 \mathrm{M} \mathrm{HClO}_{4}$ at Open Circuit Potential}

PM IRRAS spectra for samples after immersion in $0.1 \mathrm{M} \mathrm{HClO}_{4}$ for 15 min are shown in Figures S2 (CH stretching region) and S3 (1800 - $900 \mathrm{~cm}^{-1}$ region). For comparison, the PMIRRA spectra of the freshly prepared monolayer (spectrum 1 in Figure 4 ) in these figures. Thus, the assignments of the IR absorption spectra are the same as in Table S1. Taking together the XPS data and the PMIRRAS data allows the conclusion that the mere exposure of the SAM to $0.1 \mathrm{M} \mathrm{HClO}_{4}$ for 15 min cannot remove the Boc group (in contrast to the expected reactivity of the dissolved compound 2).

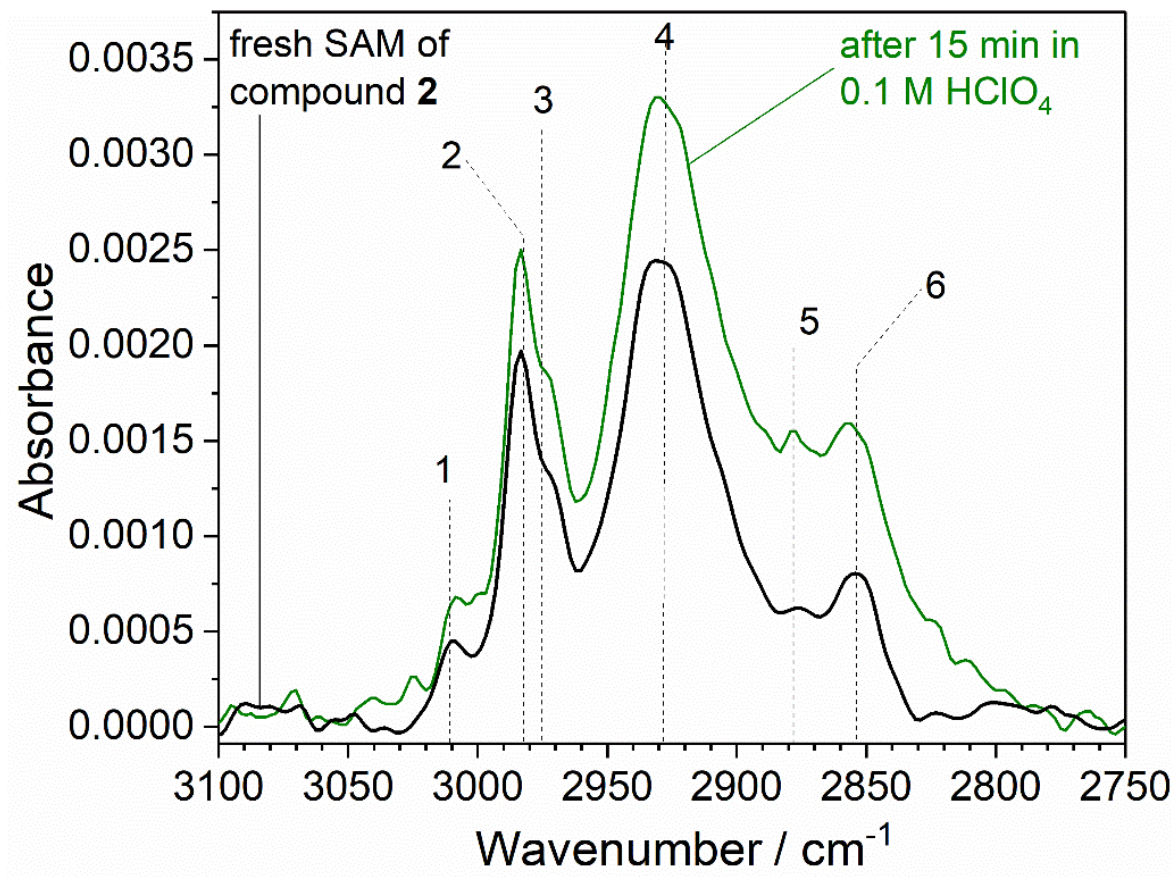

Figure S2. PM IRRAS spectra of a SAM from compound 2 (backfilled with 1-decanethiol) on an $\mathrm{Au}$ substrate after immersion in $0.1 \mathrm{M} \mathrm{HClO}_{4}$ for $15 \mathrm{~min}$ (green) in region from $3150 \mathrm{~cm}^{-1}$ to $2700 \mathrm{~cm}^{-1}$. The spectra of the fresh monolayer is shown for comparison (identical to spectrum 1 in Figure $4 \mathrm{a}$ of the main manuscript). 


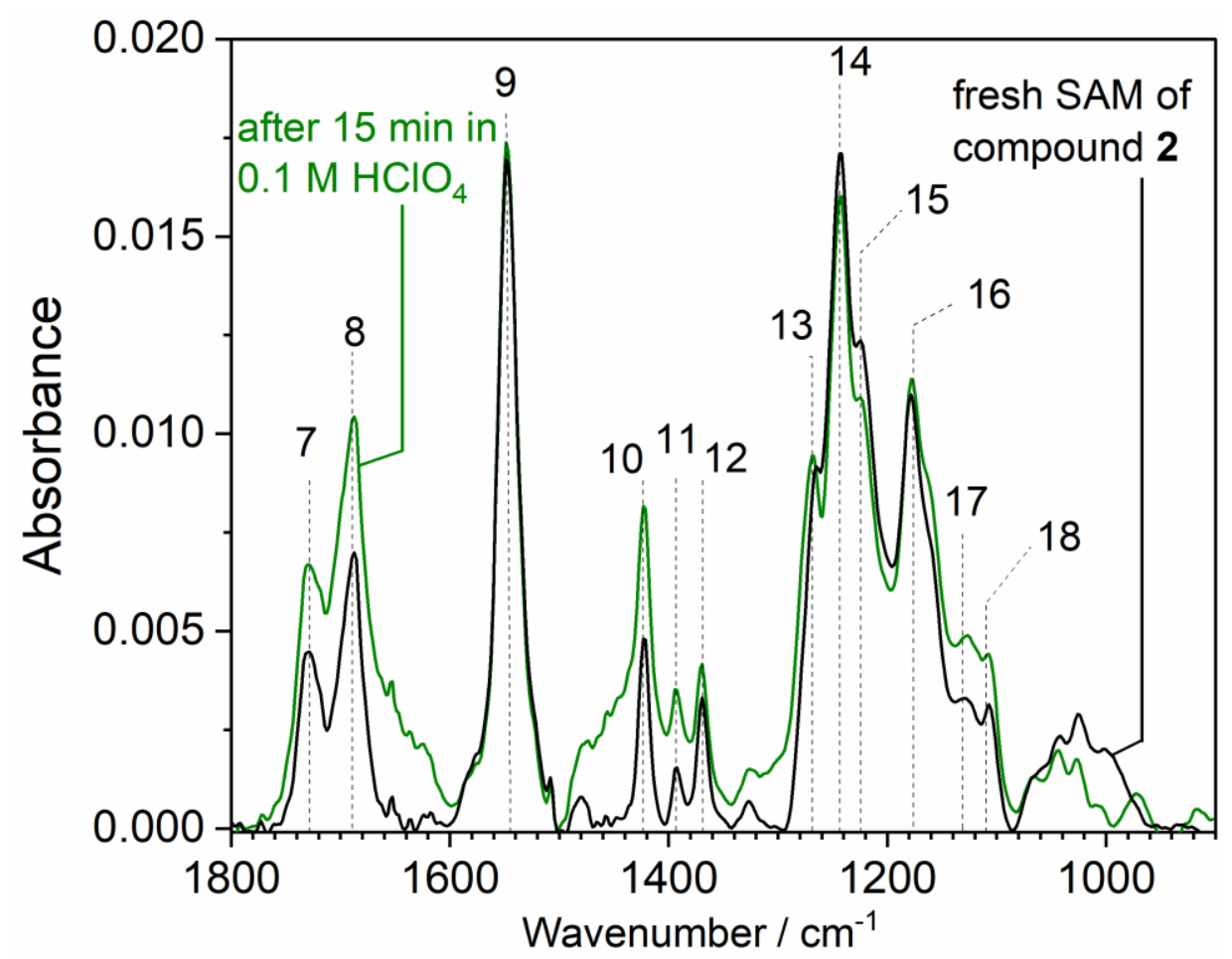

Figure S3. PM IRRAS spectra of a SAM from compound 2 (backfilled with 1-decanethiol) on an $\mathrm{Au}$ substrate after immersion in $0.1 \mathrm{M} \mathrm{HClO}_{4}$ for $15 \mathrm{~min}$ in region from $1800 \mathrm{~cm}^{-1}$ to 900 $\mathrm{cm}^{-1}$. The spectra of the fresh monolayer is shown for comparison (identical to spectrum 1 in Figure $4 \mathrm{~b}$ of the main manuscript). 


\section{SI-7 Atomic Ratio S:F after Conjugate Addition of 3-(Trifluoromethyl)aniline to the Activated SAM}

The conjugate addition of 3-(trifluoromethyl)aniline with the activated SAM is shown in Scheme 3.
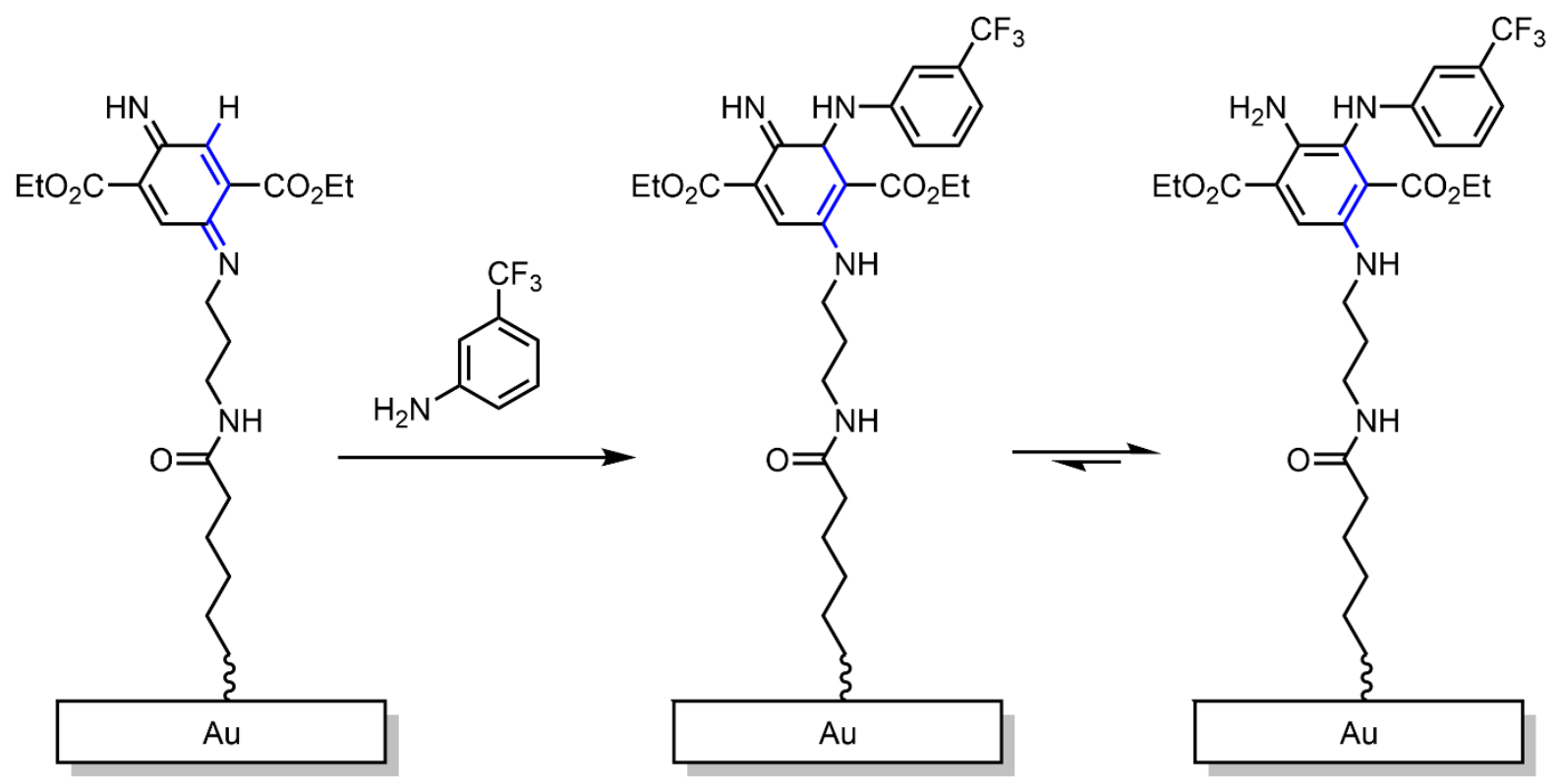

Scheme S3. Conjugate addition of 3-(trifluoromethyl)aniline with the activated SAM, specifically the quinone imine shown in Figure $2 \mathrm{~d}$ of the main manuscript.

Figure S4 shows the peak fit for the F 1s and S 2p XP spectra of an activated SAM in $0.1 \mathrm{M}$ $\mathrm{HClO}_{4}$ after potential cycling in $0.1 \mathrm{M} 3$-(trifluoromethyl)aniline. The assignment of the peaks and binding energies are summarized in Table S3.
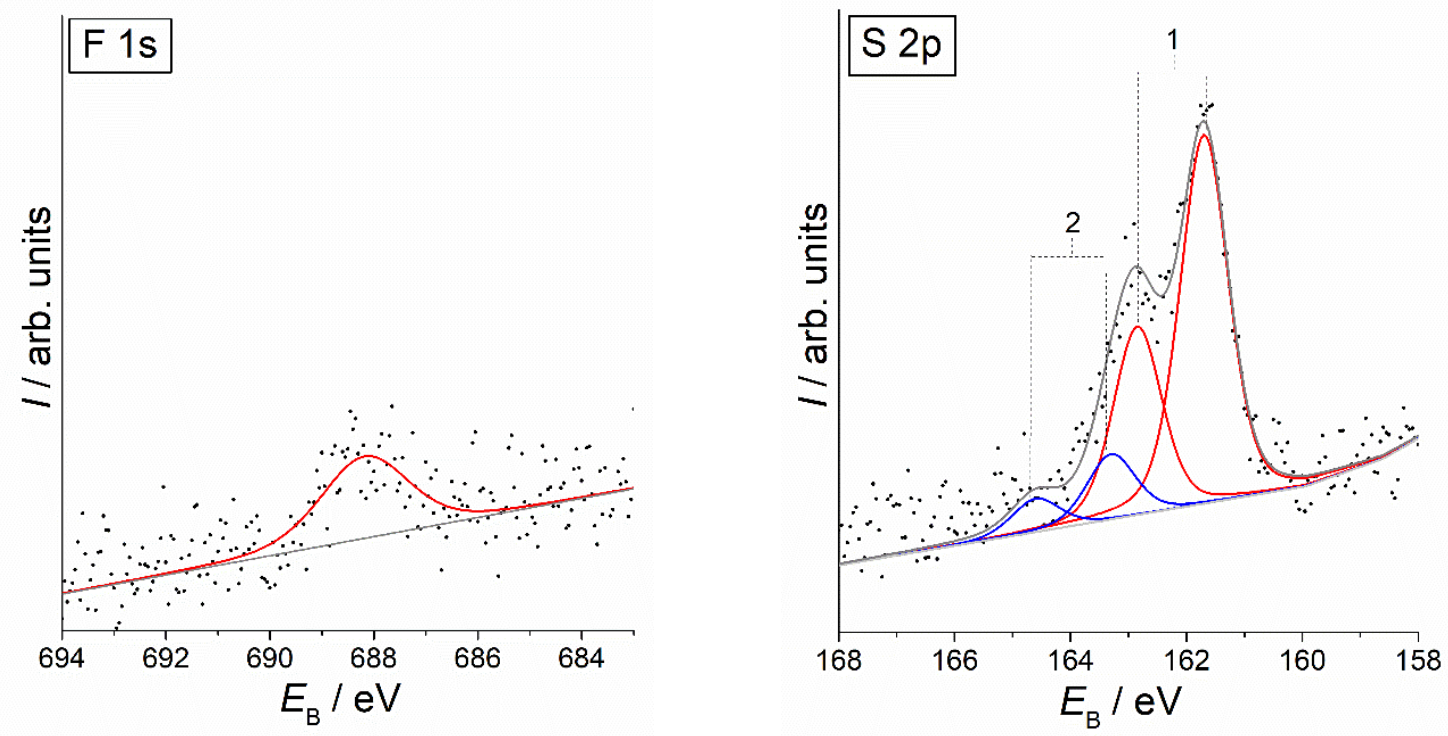
Figure S4. F 1s and S 2p XP spectra of an activated SAM on Au after potential cycling in $0.1 \mathrm{M}$ 3-(trifluoromethyl)aniline.

Table S3. Assignment of XP spectra in Figure S4.

\begin{tabular}{|l|l|c|c|c|}
\hline \multicolumn{1}{|c|}{ Signal } & \multicolumn{1}{|c|}{ Interpretation } & $\boldsymbol{E}_{\mathbf{B}} / \mathbf{e V}$ & $\mathbf{F W H M} / \mathbf{e V}$ & Reference \\
\hline $\mathrm{S} 2 \mathrm{p}_{3 / 2}$ & R-S-Au & 161.8 & 0.99 & 5 \\
\hline $\mathrm{S} \mathrm{2} \mathrm{p}_{1 / 2}$ & R-S-Au & 162.9 & 0.99 & 5 \\
\hline $\mathrm{S} \mathrm{2} \mathrm{p}_{3 / 2}$ & radiation damage & 163.3 & 0.99 & 6 \\
\hline $\mathrm{S} \mathrm{2} 2 \mathrm{p}_{1 / 2}$ & radiation damage & 164.4 & 0.99 & 6 \\
\hline F 1s & F $\mathrm{C}$ & 688.18 & 2.00 & 7 \\
\hline
\end{tabular}

The atomic ratio of $\mathrm{F}: \mathrm{S}$ is $0.15: 1$ as calculated from the integrated XPS intensities. Each molecule 2 contains $2 \mathrm{~S}$ atoms, after addition of 3-(trifluoromethyl)aniline, each reacted molecules contains $3 \mathrm{~F}$ atoms. This gives a ratio of molecules that reacted with 3-(trifluoromethyl)aniline to the total number of molecules with the lipoic acid anchor group of $0.05: 0.5=1: 10$. Considering the results from cyclic volammetry that $10 \%$ of the originally present compound $\mathbf{2}$ in the SAM was converted to the new compound with reversible surface voltammetry, this corresponds to a $100 \%$ conversion of this compound. The estimation neglects the small content of 1-decanthiol that would slightly contribute to the $S 2 p$ signal but makes less then $10 \%$ of the initial monolayer. 


\section{SI-8 Additional Example for Conjugate Addition}

The conjugate addition was tested with further reagents. Figure S5 shows the cyclic voltammograms recorded during the conjugate addition of 4-aminobenzoic acid. The peak $\mathrm{II}_{\mathrm{a}} / \mathrm{II}_{\mathrm{c}}$ of the activated SAM successively decrease in intensity as the 4-aminobenzoic acid is bound.

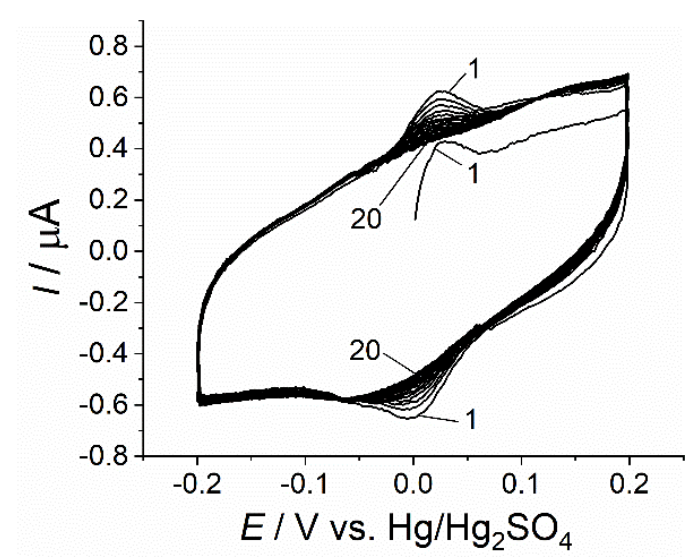

Figure S5. a) Twenty consecutive cyclic voltammograms at $v=20 \mathrm{mV} \mathrm{s}^{-1}$ during the reaction of the activated SAM in $0.1 \mathrm{M}$ 4-aminobenzoic acid to $0.1 \mathrm{M} \mathrm{HClO}_{4}$ showing the decrease of the signal of the reversible, surface-bound redox couple. The original SAM was prepared from compound 2, backfilled with 1-decanthiol and activated by electrooxidation in $0.1 \mathrm{M} \mathrm{HClO}_{4}$. The numbers indicate the potential cycle. 


\section{References}

(1) Buschbeck, L.; Christoffers, J. Orthogonally Protected Diaminoterephthalate Scaffolds: Installation of Two Functional Units at the Chromophore. J. Org. Chem. 2018, 83, 4002-4014.

(2) Günzler, H.; Gremlich, H.-U. IR Spectroscopy: An Introduction; Wiley-VCH: Weinheim, 2002.

(3) Hesse, M.; Meier, H.; Zeeh, B. Spektroskopische Methoden in der organischen Chemie, 4th ed.; Georg Thieme Verlag: Stuttgart, New York, 1991.

(4) Miyazawa, T.; Fukushima, K.; Ideguchi, Y. Molecular Vibration and Structure of High Polymers. III. Polarized Infrared Spectra, Normal Vibration, and Helical Conformation at Polyethylene Glycol. J. Chem. Phys. 1962, 37, 2764-2776.

(5) Castner, D. G.; Hinds, K.; Grainger, D. W. X-Ray Photoelectron Spectroscopy Sulfur 2p Study of Organic Thiol and Disulfide Binding Interactions with Gold Surfaces. Langmuir 1996, $12,5083-5086$.

(6) Duwez, A.-S. Exploiting Electron Spectroscopies to Probe the Structure and Organization of Self-Assembled Monolayers: A Review. J. Electron Spectrosc. Relat. Phenom. 2004, 134, 97-138.

(7) Ford, K.; Battersby, B. J.; Wood, B. J.; Gentle, I. R. The Production and Verification of Pristine Semi-Fluorinated Thiol Monolayers on Gold. J. Colloid Interface Sci. 2012, 370, 162169. 